\title{
Intravesical migration of an intrauterine device detected in a pregnant woman
}

\author{
Migraci Tosun, MD; Handan Celik, MD; Erhan Yavuz, MD; Mehmet B. Çetinkaya, MD
}

\begin{abstract}
The intrauterine device (IUD) is common method of contraception among women because of its low cost and high efficacy. Perforations are possible; most perforations occur at the time of insertion, yet the complication can occur with a previously inserted IUD. Perforation of the bladder by an IUD is extremely rare. In this report, we present a case in which the IUD perforated the uterus and migrated to the bladder. At the time of the diagnosis, the patient was 8 weeks pregnant.
\end{abstract}

Can Urol Assoc J 2010;4(5):E141-143

\section{Introduction}

Intrauterine devices (IUD) have been used for more than 3 decades. More than 100 million women worldwide have been using the IUD. ${ }^{1,2}$ Uterine perforation during the insertion is an uncommon complication of IUD and the incidence ranges from 0.2 to 9.6 per 1000 insertions.

\section{Case report}

A 28-year-old pregnant woman (gravida 3, para 2) was referred to Ondokuz Mayıs University Obstetric and Gynecology Department for migration of IUD into the bladder. The dislocation of the IUD was diagnosed by an obstetrician when the patient was examined for secondary amenorrhea and suprapubic pain. She had been complaining of lower abdominal pain, frequency and dysuria for the past 3 months. Her last menstrual date was eight weeks ago. Her medical and gynecologic histories were unremarkable. She had two deliveries with Cesarean section. She had a Copper T 380 type IUD placed by a gynecologist 1.5 years ago about 12 weeks after her last Cesarean section. In gynecologic examination, the cervix was closed and the IUD threads could not be observed. An ultrasound examination revealed echogenic intravesical lesion measuring about $25 \mathrm{~mm}$ in length suggestive of the IUD (Fig. 1). A gestational sac with an embryo of 8 weeks was also detected. Cystoscopy was performed in general anesthesia, during which it was observed that the tail and body of the IUD penetrated the bladder mucosa and became embedded in the posterior wall of the bladder (Fig. 2). The tail of IUD was grasped by forceps and easily removed as a whole unit by pulling it through the perforation site and gently taken out through the cystoscope. At the patient's request, the pregnancy was terminated by dilatation and curettage. A Foley catheter was left in bladder for 5 days. The patient was discharged 3 days after the IUD removal without complication.

\section{Discussion}

Several cases of IUD perforation have been reported. ${ }^{3,4,5}$ Due to the asymptomatic nature of the perforation, the true incidence of the uterus perforation by an IUD is most likely higher than reported. ${ }^{6}$ The exact mechanism that causes uterine perforation and migration of the IUD is not entirely known. The most important factor related with this complication is probably the operator experience in IUD application. There are also many factors that affect uterine perforation, such as the uterine size, position, timing of the insertion, congenital uterine anomalies and former operations. ${ }^{2}$ Previous Cesarean section was a risk factor of uterine perforation by IUD. In the present case, the patient had 2 Cesarean sections prior to the IUD insertion.

The IUD can be inserted into the uterus in the postpartum period. However, the uterine atrophy and thinning of the uterine walls due to hypoestrogenism, involution of uterus, strong uterine contractions and soft consistency of the uterus can increase the risk of perforation. ${ }^{7,8}$ It was, therefore, suggested to postpone the IUD insertion until 3 months after delivery to be safe. ${ }^{7,4}$ Spontaneous uterine contractions, bowel peristalsis and bladder contractions are other physiological mechanisms that may cause spontaneous migration of the IUD. ${ }^{9}$ Uterine perforation can occur at the time of the insertion or at any other time after the insertion. In the present case, we could not determine whether the perforation occurred at the time of insertion or later, but as erosion of 


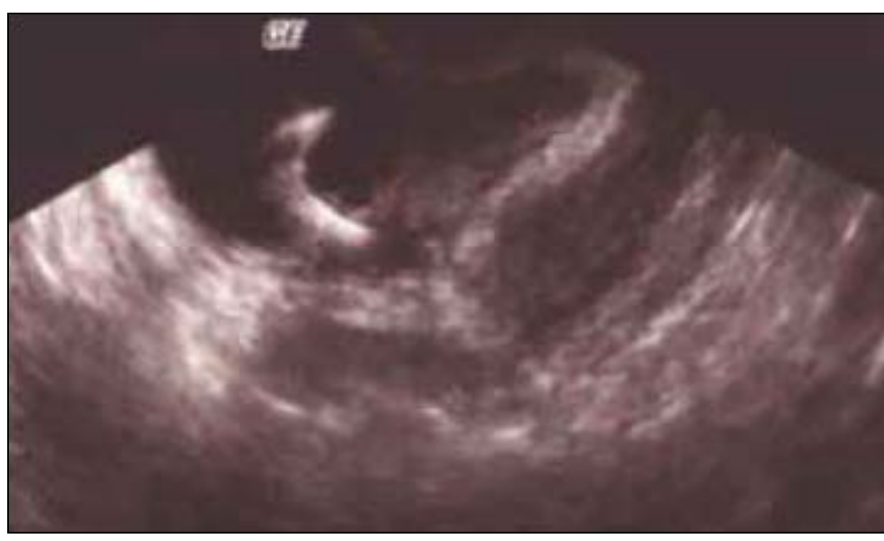

Fig. 1. Sonographic image of intrauterine device seen in bladder.

bladder wall is mostly symptomatic, the presence of symptoms in 3 months suggested that the IUD migration into the bladder was recent. It was also possible that migration of IUD into the bladder occurred earlier, but did not cause any symptoms.

Dysüria, suprapubic pain, recurrent urinary tract infections, hematuria, chronic pelvic pain and irritation on voiding are clinical symptoms related with IUD migration into the bladder. ${ }^{5,10}$ The presence of these symptoms and the history of IUD insertion with failure to locate its threads may indicate that the device has been dislocated. In the present case, the patient complained only of dysüria and mild suprapubic pain for 3 months. Secondary amenorrhea was the main reason for the visit to the gynecologist.

Sonography with transvaginal and transabdominal approaches is a useful method to detect IUD migration. ${ }^{11-13}$ In some cases, computed tomography is needed for diagnosis. ${ }^{14}$ In the present case, the migration of the IUD into the bladder was diagnosed by abdominopelvic sonography and cystoscopy. Intravesical migration of IUD is often associated with calculus formation. ${ }^{14-16}$ The presence of calculus in the plain X-ray of the urinary system with the absence of IUD strings in pelvic examination increases the suspicion of IUD migration into the bladder. It should be remembered that calculus formation does not occur in all intravesical IUDs, so the absence of calculus formation around IUD does not eliminate the suspicion of intravesical IUD.

\section{Conclusion}

Every case of a missing IUD, even with the presence of a pregnancy, must be investigated carefully for uterine perforation. The possibility of IUD migration into other intraabdominal organs is always possible and should be discussed with patients. Migration of an IUD into the bladder should be considered in woman having newly onset, unexplained, persistent urinary tract symptoms. Any displaced IUD should be removed due to potential complications.

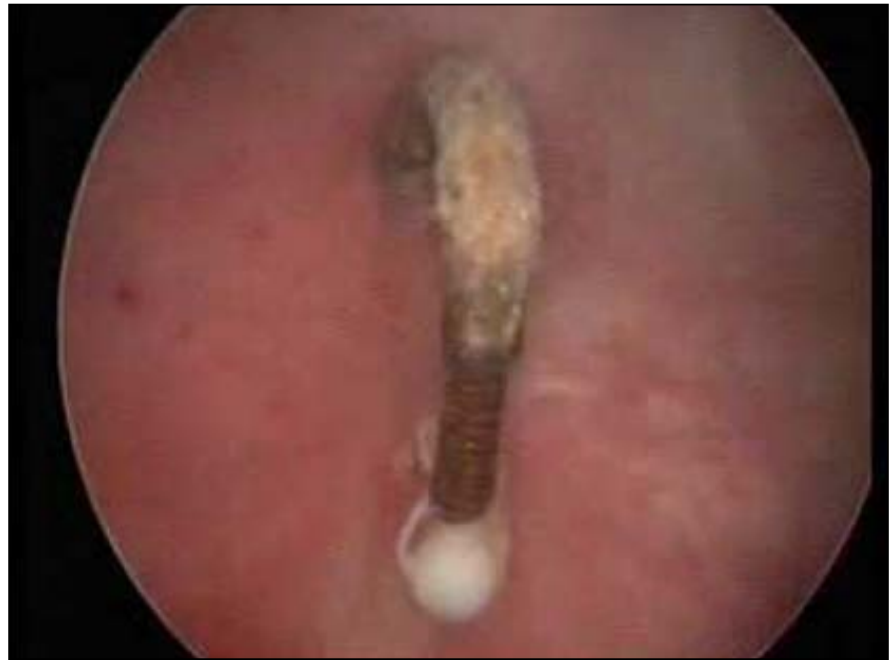

Fig. 2. Intravesical position of intrauterine device revealed by cystoscopy.

Department of Obstetrics and Gynecology, Ondokuz Mayis, Samsun, Turkey

Competing interests: None declared.

This paper has been peer-reviewed.

\section{References}

1. Oruc $\mathrm{S}$, Vatansever HS, Karaer 0 , et al. Changes in distribütion patterns of integrins in endometrium in copper T380 intrauterine device users. Acta Histochem 2005; 107:95-103.

2. Tuncay $Y A$, Tuncay $E$, Güzin $K$, et al. Transuterine migration as a complication of intrauterine contraceptive devices: six case reports. Eur J Contracept Reprod Health Care 2004;9:194-200.

3. Dabbas M, Maaita M. Ureteric calculus around an intrauterine contraceptive device. J Obstet Gynecol 2002;22:101.

4. Ohana $E$, Sheiner E, Leron E, et al. Appendix perforation by an intrauterine contraceptive device. Eur J Obstet Gynecol Reprod Biol 2000;88:129-31.

5. Markovitch 0 , Klein Z, Gidoni Y, et al. Extra-uterine mislocated IUD: Is surgical removal mandatory? Contraception 2002; 66:105-8.

6. Thomalla JV. Perforation of urinary bladder by intrauterine device. Urology 1986;27:260-4.

7. Calı kan E, Oztürk N, Dilbaz BO, et al. Analysis of risk factors associated with uterine perforation by intrauterine devices. Eur I Contracept Reprod Health Care 2003;8:150-5.

8. Hoscan $M B$, Kosar $A$, Gümüstas $U$, et al. Intravesical migration of the intrauterine device resulting in pregnancy. Int J Urol 2006;13:301-2.

9. Eke N, Okpani A0. Extrauterine translocated contraceptive device: a presentation of five cases and revisit of the enigmatic issues of iatrogenic perforation and migration. Afr J Reprod Health 2003;7:117-23.

10. Ozcelik $B$, Serin IS, Basbu $M$, et al. Differential diagnosis of intrauterine device migrating to bladder using radiographic image of calculus formation and review of literature. Eur J Obstet Reprod Biol 2003;108:94-7.

11. Sepulveda WH, Ciuffardi I, Olivari A, et al. Sonographic diagnosis of bladder perforation by an intrauterine device. A case report. J Reprod Med 1993;8:911-3.

12. Caspi B, Rabinerson D, Appelman Z, et al. Penetration of the bladder by a perforating intrauterine contraceptive device: a sonographic diagnosis. Ultrasound Obstet Gynecol 1996;7:458-60.

13. Mahmutyazıcıo lu K, Ozdemir H, Ozkan P. Migration of an intrauterine contraceptive device to the urinary bladder: sonographic findings. J Clin Ultrasound 2002;30:496-8.

14. El-Hefnawy AS, E-Nahas AR, Osman Y, et al. Urinary complications of migrated intrauterine contraceptive device. Int Urogynecol J 2008;19:241-5.

15. Dede FS, Dilbaz B, Sahin D, et al. Vesical calculus formation around a migrated copper-T 380-A. Eur J Contracept Reprod Health Care 2006;11:50-2. 
Intravesical migration of an intrauterine device

16. Singh I. Intravesical Cu-T migration: an atypical and infrequent cause of vesical calculus. Int Urol Nephrol 2007;39:457-9.
Correspondence: Dr. Handan Celik, Ondokuz Mayis University Hospital, Department of Obstetrics \& Gynecology, 55139 Kurupelit/Samsun, Turkey; drhandancelik@hotmail.com 